\title{
A THEORETICAL QUANTUM STUDY OF THE ELECTRONIC PROPERTIES OF MENTOXY DICHLORO PHOSPHOROUS $\left(\mathrm{C}_{10} \mathrm{H}_{19} \mathrm{OPCl}_{2}\right)$
}

\author{
AMIR LASHGARI ${ }^{a}$, SHAHRIAR GHAMAMI ${ }^{a}$, M. GOVINDARAJAN ${ }^{b}$, GUILLERMO SALGADO-MORÁN ${ }^{c}$, \\ PAOLA MONTES ROMERO' ${ }^{c}$ LORENA GERLI CANDIA ${ }^{*}$
}

\author{
a Department of Chemistry, Faculty of Science, Imam Khomeini International University, Qazvin, 34148-96818, \\ ${ }^{b}$ Department of Physics, Avvaiyar Government College for Women (AGCW), Karaikal, Puducherry 609602, India \\ 'Departamento de Ciencias Químicas, Facultad de Ciencias Exactas, Universidad Andrés Bello, Sede Concepción, Concepción, Chile \\ $d^{*}$ Departamento de Química Ambiental, Facultad de Ciencias, Universidad Católica de la Santísima Concepción, Concepción, Chile
}

\section{ABSTRACT}

A theoretical quantum study of the organophosphorus compound with formula $\mathrm{C}_{10} \mathrm{H}_{10} \mathrm{OPCl}_{2}(\mathrm{MEPCL} 2)$ was carried out. The results of the calculations show excellent agreement between experimental and computed frequencies evaluated at the B3LYP/6-311++G(d,p) level of theory. A study of the electronic properties, such as excitation energies and wavelengths were performed employing the time-dependent DFT (TD-DFT) method. Global a chemical reactivity of MEPCL2 was analyzed through global reactivity descriptors, while its local reactivity was analyzed by mean maps of the electrostatic potential. Also, the orbital energies values suggest that a charge transfer is occurring within the molecule.

Keywords: Phosphorous compound; DFT; HF; HOMO-LUMO.

\section{INTRODUCTION}

Organophosphorus compounds are of great interest because many biological processes such as energy transfer, bone synthesis, amino acid synthesis, among others are related to them ${ }^{1}$. Consequently, it is not so strange that many researchers are studying them to understand their role in biological systems ${ }^{2-4}$. Moreover, phosphorus compounds are employed in numerous synthetic procedures to manufacture detergents, fertilizers, pesticides, toxic industrial phosphate esters, natural products, among others ${ }^{5,6}$.

Recently, mentoxy dichloro phosphorous $\left(\mathrm{C}_{10} \mathrm{H}_{19} \mathrm{OPCl}_{2}\right)$ (MEPCL2) was synthesized from the reaction of 2-(2-propyl)-5-methyl-1-cyclohexanol (menthol) with $\mathrm{PCl}_{3}$. This new organophosphorus compound exhibits a maximum absorbance at $227 \mathrm{~nm}$, this value indicates that MEPCL2 has important absorption properties in the visible region of the electromagnetic spectra, by which may useful in the fabrication of photovoltaic devices. However, to the best of our knowledge, there is no information about the electronic properties and the chemical behavior of MEPCL2. Thus, it is necessary to get a deeper knowledge about this compound, to identify its potential uses and applications. In this sense, the evaluation of these properties may result expensive and complicated from the experimental point of view. However, the accepted theories of the quantum chemistry provide advantages to analyze the electronic properties and reactivity of molecules reliably ${ }^{7}$. Therefore, in the present work, we perform a computational and theoretical quantum study about the electronic properties and chemical reactivity exhibited by MEPCL2. We consider that this kind of study will contribute to getting a better understanding of the chemical behavior of this new organophosphorus compound.

\section{METHODOLOGY}

The entire quantum chemical calculations have been performed at HF and DFT (B3LYP) methods with 6-311++G(d,p) basis sets using the Gaussian 03W program $^{8}$. The optimized structural parameters have been evaluated for the calculations of vibrational frequencies by assuming Cs point group symmetry. At the optimized geometry for the title molecule no imaginary frequency modes were obtained, therefore there is a true minimum on the potential energy surface was found. As a result, the unscaled calculated frequencies, reduced masses, force constants, infrared intensities, and depolarization ratios are obtained. In order to fit the theoretical wavenumbers to the experimental, the scaling factors have been introduced by using a least square optimization of the computed to the experimental data. Vibrational frequencies are scaled as 0.9067 for HF and 0.961 for $\mathrm{B}^{3} \mathrm{LYP}^{9}$ to account for systematic errors caused by basis set incompleteness, neglect of electron correlation and vibrational anharmonicity. The assignments of the compound are calculated by using VEDA program ${ }^{10}$.

The electronic absorption spectra for optimized molecule calculated with the time-dependent DFT (TD-DFT) at B3LYP/6-311++G(d,p) level in gas phase and solvent (Acetonitrile, chloroform, and water). The ${ }^{13} \mathrm{C}$ nuclear magnetic resonance (NMR) chemical shifts of the molecule were calculated by the gauge-independent atomic orbital (GIAO) method in $\mathrm{CDCl}_{3}$ and compared with experimental results.

\section{RESULTS AND DISCUSSION}

3.1. Molecular geometry

The geometry optimization of MEPCL2, see Fig. 1, was carried out at the $\mathrm{HF} / 6-311++\mathrm{G}(\mathrm{d}, \mathrm{p})$ and B3LYP//6-311++G(d,p) levels of theory.

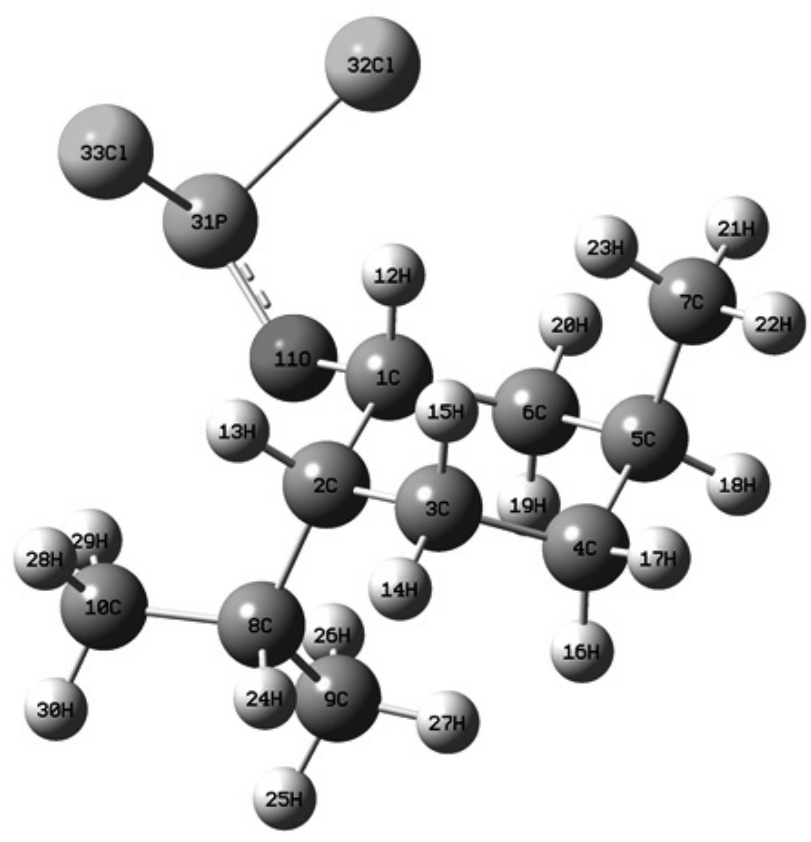

Fig. 1. Optimized molecular structure of MEPCL2 with atom numbering.

No imaginary frequencies were obtained, which ensures us that each gradient optimization located corresponds to true minimum energy on the energy potential surface. The selected optimized structural parameters, bond lengths and bond angles of the title compound are reported in Table 1. From 
this table, it is possible to observe that the bond lengths and bond angles values calculated at the HF/6-311++G(d,p) and B3LYP/6-311++G(d,p) levels of theory compare favorably well with those reported in the literature. A linear fit of the optimized data, see Fig. 2 suggests that the bond lengths values calculated at the HF/6-311++G(d,p) level is slightly better than the geometry obtained at the B3LYP/6-311++G(d,p) level. However, this difference is in the order of the error associated with the resolution of the wavefunction when numerical algorithms are employed. Thus, no significant differences were obtained, which is indicative that the electronic correlation has a little effect on the molecular geometry of the MEPCL2.

Table 1. Selected optimized parameters of MEPCL2

\begin{tabular}{|c|c|c|c|c|c|c|c|}
\hline Bond length & $\begin{array}{c}\mathrm{HF} / \\
6-311++ \\
\mathrm{G}(\mathrm{d}, \mathrm{p})(\AA)\end{array}$ & $\begin{array}{c}\text { B3LYP/6-311++ } \\
\text { G(d,p) }(\AA)\end{array}$ & $\begin{array}{l}\text { Experimental } \\
\text { Value }(\AA)^{7}\end{array}$ & Bond angle & $\begin{array}{c}\mathrm{HF} / \\
6-311++ \\
\mathrm{G}(\mathrm{d}, \mathrm{p})\left(^{\circ}\right)\end{array}$ & $\begin{array}{c}\text { B3LYP/ } \\
6-311++ \\
\mathrm{G}(\mathrm{d}, \mathrm{p})\left({ }^{\circ}\right)\end{array}$ & $\begin{array}{c}\text { Experimental } \\
\text { Value }\left({ }^{\circ}\right)^{7}\end{array}$ \\
\hline $\mathrm{C} 1-\mathrm{H} 12$ & 1.083 & 1.093 & & H12-C1-O11 & 107.0 & 106.4 & \\
\hline $\mathrm{C} 2-\mathrm{H} 13$ & 1.085 & 1.095 & 0.970 & $\mathrm{H} 13-\mathrm{C} 2-\mathrm{C} 3$ & 105.6 & 105.8 & \\
\hline C3-H14 & 1.086 & 1.094 & 0.970 & H14-C3-H15 & 105.8 & 105.7 & 108.1 \\
\hline $\mathrm{C} 3-\mathrm{H} 15$ & 1.088 & 1.096 & 0.970 & $\mathrm{H} 15-\mathrm{C} 3-\mathrm{C} 4$ & 108.9 & 109.0 & 109.5 \\
\hline C4-H16 & 1.086 & 1.094 & 0.970 & H16-C4-C5 & 109.2 & 109.3 & 109.5 \\
\hline C4-H17 & 1.087 & 1.095 & 0.970 & H17-C4-H16 & 106.2 & 106.1 & 108.1 \\
\hline $\mathrm{C} 5-\mathrm{H} 18$ & 1.088 & 1.096 & 0.970 & H18-C5-C7 & 106.6 & 106.9 & 107.9 \\
\hline C6-H19 & 1.082 & 1.090 & 0.970 & H19-C6-C1 & 109.2 & 109.2 & 109.3 \\
\hline C6-H20 & 1.085 & 1.094 & 0.970 & H20-C6-H19 & 106.8 & 106.9 & 107.9 \\
\hline $\mathrm{C} 7-\mathrm{H} 21$ & 1.086 & 1.094 & & $\mathrm{H} 21-\mathrm{C} 7-\mathrm{H} 23$ & 107.4 & 107.4 & \\
\hline $\mathrm{C} 7-\mathrm{H} 22$ & 1.087 & 1.094 & & $\mathrm{H} 22-\mathrm{C} 7-\mathrm{H} 21$ & 107.7 & 107.8 & \\
\hline $\mathrm{C} 7-\mathrm{H} 23$ & 1.086 & 1.093 & & $\mathrm{H} 23-\mathrm{C} 7-\mathrm{H} 22$ & 107.4 & 107.3 & \\
\hline $\mathrm{C} 8-\mathrm{H} 24$ & 1.088 & 1.098 & & $\mathrm{H} 24-\mathrm{C} 8-\mathrm{C} 10$ & 106.0 & 106.2 & \\
\hline $\mathrm{C} 9-\mathrm{H} 25$ & 1.087 & 1.094 & & $\mathrm{H} 25-\mathrm{C} 9-\mathrm{H} 27$ & 107.1 & 107.1 & \\
\hline $\mathrm{C} 9-\mathrm{H} 26$ & 1.084 & 1.093 & & $\mathrm{H} 26-\mathrm{C} 9-\mathrm{H} 25$ & 107.5 & 107.3 & \\
\hline $\mathrm{C} 9-\mathrm{H} 27$ & 1.083 & 1.091 & & $\mathrm{H} 27-\mathrm{C} 9-\mathrm{H} 26$ & 108.5 & 108.4 & \\
\hline $\mathrm{C} 10-\mathrm{H} 28$ & 1.086 & 1.094 & & $\mathrm{H} 28-\mathrm{C} 10-\mathrm{H} 30$ & 107.7 & 107.7 & \\
\hline $\mathrm{C} 10-\mathrm{H} 29$ & 1.084 & 1.092 & & H29-C10-H28 & 108.0 & 108.0 & \\
\hline $\mathrm{C} 10-\mathrm{H} 30$ & 1.087 & 1.094 & & H30-C10-H29 & 107.6 & 107.7 & \\
\hline C1-C6 & 1.526 & 1.528 & 1.534 & $\mathrm{C} 4-\mathrm{C} 3-\mathrm{C} 2$ & 114.6 & 114.5 & 110.5 \\
\hline $\mathrm{C} 4-\mathrm{C} 3$ & 1.531 & 1.535 & 1.521 & $\mathrm{C} 2-\mathrm{C} 1-\mathrm{C} 6$ & 115.7 & 115.9 & 110.8 \\
\hline $\mathrm{C} 2-\mathrm{C} 1$ & 1.537 & 1.540 & 1.532 & $\mathrm{C} 7-\mathrm{C} 5-\mathrm{C} 6$ & 112.6 & 112.5 & \\
\hline $\mathrm{C} 7-\mathrm{C} 5$ & 1.537 & 1.538 & & $\mathrm{C} 9-\mathrm{C} 8-\mathrm{C} 2$ & 118.4 & 118.1 & \\
\hline $\mathrm{C} 9-\mathrm{C} 8$ & 1.534 & 1.539 & & $\mathrm{C} 10-\mathrm{C} 8-\mathrm{C} 9$ & 110.1 & 110.0 & \\
\hline $\mathrm{C} 5-\mathrm{C} 4$ & 1.535 & 1.543 & 1.523 & C6-C5-C4 & 109.1 & 109.2 & 111.7 \\
\hline $\mathrm{C} 10-\mathrm{C} 8$ & 1.539 & 1.540 & & $\mathrm{C} 8-\mathrm{C} 2-\mathrm{C} 3$ & 107.7 & 107.6 & \\
\hline $\mathrm{C} 6-\mathrm{C} 5$ & 1.536 & 1.546 & 1.525 & O11-C1-C6 & 113.9 & 113.8 & \\
\hline $\mathrm{C} 3-\mathrm{C} 2$ & 1.546 & 1.552 & 1.513 & $\mathrm{P} 31-\mathrm{O} 11-\mathrm{C} 1$ & 132.3 & 130.1 & \\
\hline $\mathrm{C} 8-\mathrm{C} 2$ & 1.447 & 1.567 & & Cl32-P31-O11 & 102.4 & 102.8 & \\
\hline O11-C1 & 1.563 & 1.576 & & $\mathrm{Cl33}-\mathrm{P} 31-\mathrm{Cl} 32$ & 98.4 & 98.5 & \\
\hline P31-O11 & 1.568 & 1.600 & & & & & \\
\hline Cl32-P31 & 2.093 & 2.141 & & & & & \\
\hline Cl33-P31 & 2.093 & 2.141 & & & & & \\
\hline
\end{tabular}




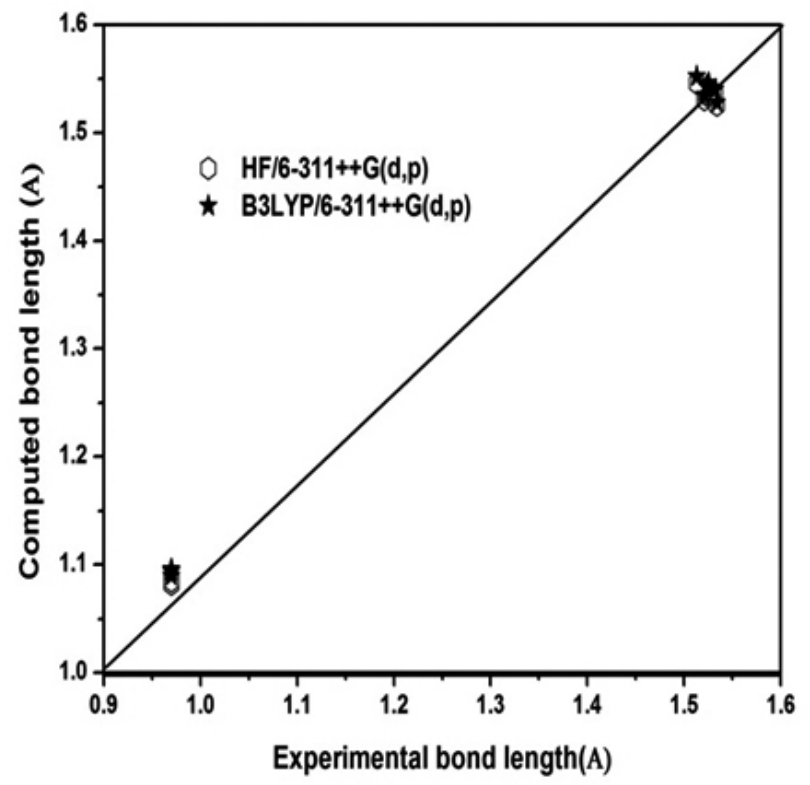

Fig. 2. Linear fit bond length and bond angle.

\subsection{Vibrational analysis}

The number of potential active fundamental vibrations of a non-linear molecule which contains $\mathrm{N}$ atoms is equal to (3N-6), apart from three translational and three rotational degrees of freedom. Therefore, MEPCL2 molecule has 33 atoms with 93 normal modes of vibrations. In the present work, we have done a detailed vibrational assignment of the experimental wavenumbers reported in a previous work, through the comparison with theoretically scaled wavenumbers evaluated at the HF/6-311++G(d,p) and B3LYP/6-311++G(d,p) levels of theory. In order to fit the theoretical wavenumbers to the experimental data,

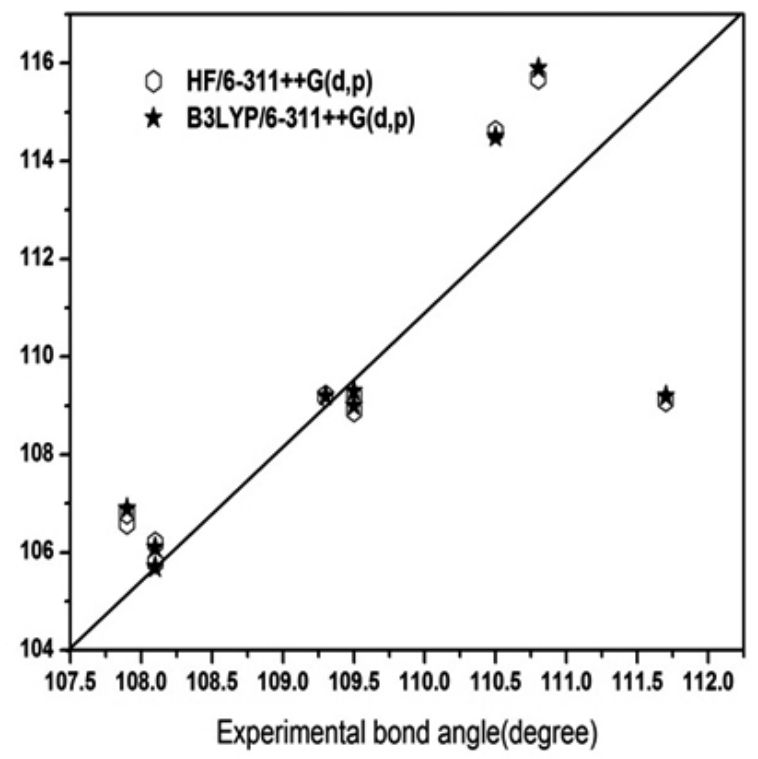

the scaling factors have been introduced by using a least square optimization of the computed to the experimental data. Vibrational frequencies are scaled as 0.9067 for $\mathrm{HF}$ and 0.961 for $\mathrm{B}^{2} \mathrm{LYP}^{10}$ to take into account the systematic errors caused by basis set incompleteness, neglect of electron correlation, in the case of HF calculations, and vibrational anharmonicity. The assignments of the compound are calculated by using VEDA program ${ }^{10}$. The calculated experimental and scaled frequencies using HF and DFT (B3LYP) with the $6-311++\mathrm{G}(\mathrm{d}, \mathrm{p})$ basis set are listed in Table 2 .

Table 2. Detailed vibrational assignments of observed and computed wavenumbers of MEPCL2.

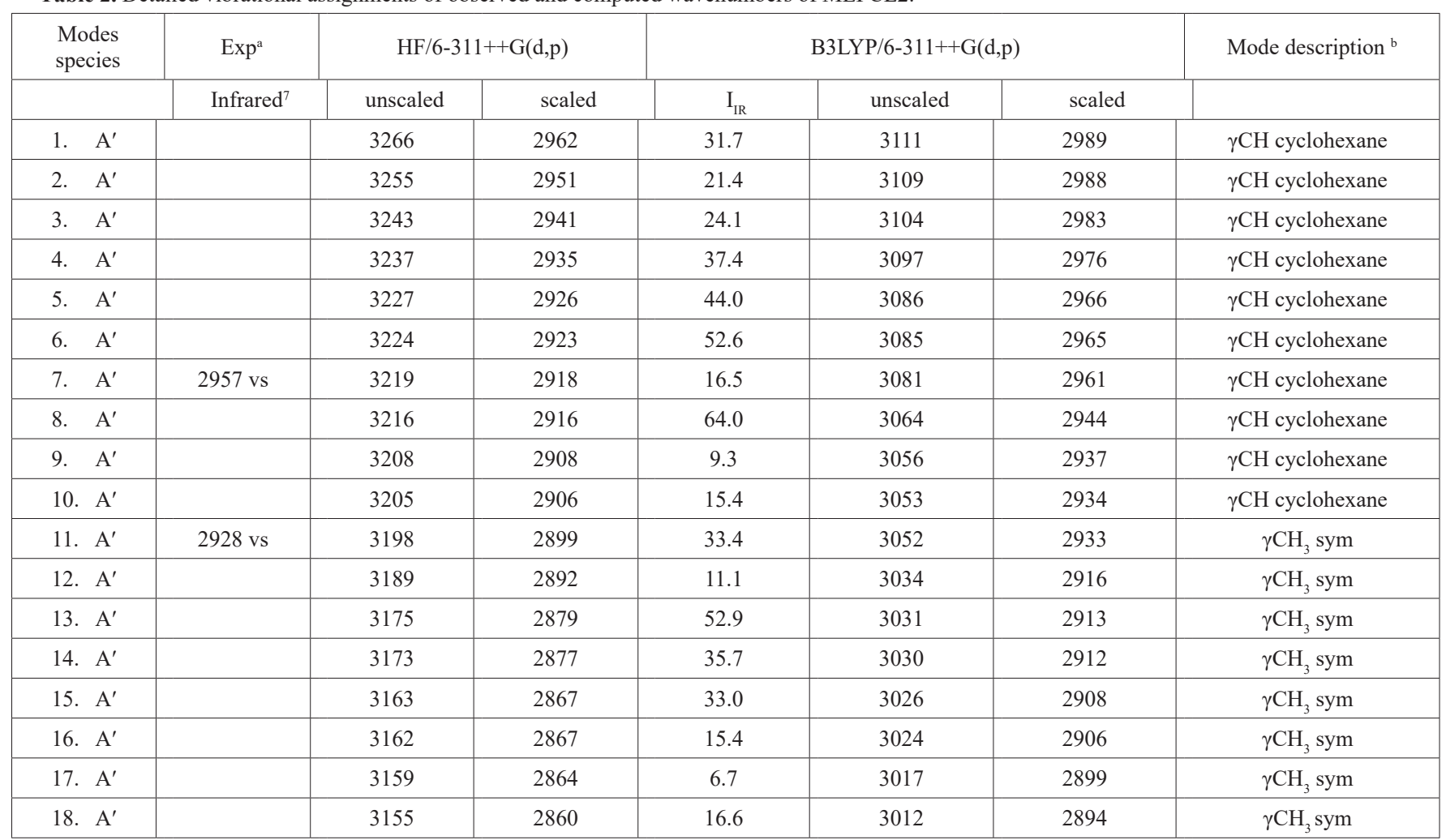




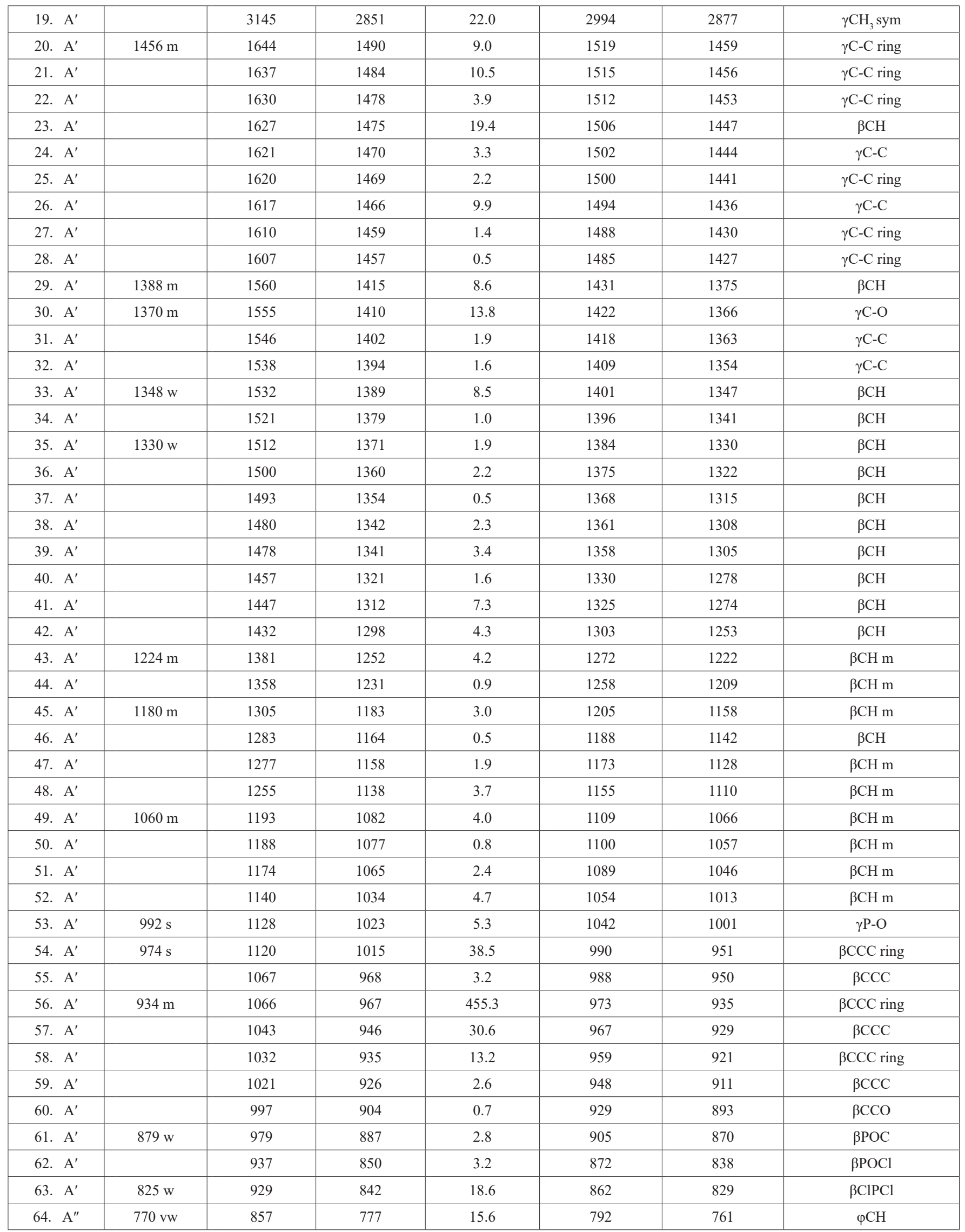




\begin{tabular}{|c|c|c|c|c|c|c|c|}
\hline 65. $\mathrm{A}^{\prime \prime}$ & & 829 & 752 & 4.3 & 774 & 744 & $\varphi \mathrm{CH}$ \\
\hline 66. $\mathrm{A}^{\prime \prime}$ & & 794 & 720 & 1.6 & 745 & 716 & $\varphi \mathrm{CH}$ \\
\hline 67. $\mathrm{A}^{\prime \prime}$ & & 723 & 656 & 3.1 & 670 & 644 & $\varphi \mathrm{CH}$ \\
\hline 68. $\mathrm{A}^{\prime \prime}$ & $586 \mathrm{vw}$ & 646 & 585 & 2.8 & 604 & 581 & $\varphi \mathrm{CH}$ \\
\hline 69. $\mathrm{A}^{\prime \prime}$ & $495 \mathrm{w}$ & 582 & 527 & 1.6 & 543 & 522 & $\varphi \mathrm{CH}$ \\
\hline 70. $\mathrm{A}^{\prime \prime}$ & $447 \mathrm{vw}$ & 535 & 485 & 64.7 & 482 & 463 & $\gamma \mathrm{P}-\mathrm{Cl}$ \\
\hline 71. $\mathrm{A}^{\prime \prime}$ & & 499 & 452 & 18.9 & 440 & 423 & $\gamma \mathrm{P}-\mathrm{Cl}$ \\
\hline 72. $\mathrm{A}^{\prime \prime}$ & & 469 & 425 & 108.2 & 428 & 411 & $\varphi \mathrm{CH} \mathrm{m}$ \\
\hline 73. $\mathrm{A}^{\prime \prime}$ & & 457 & 414 & 40.4 & 414 & 398 & $\varphi \mathrm{CH} \mathrm{m}$ \\
\hline 74. $\mathrm{A}^{\prime \prime}$ & & 454 & 411 & 15.4 & 411 & 395 & $\varphi \mathrm{CH} \mathrm{m}$ \\
\hline 75. $\mathrm{A}^{\prime \prime}$ & & 424 & 384 & 3.5 & 390 & 374 & $\varphi \mathrm{CH} \mathrm{m}$ \\
\hline 76. $\mathrm{A}^{\prime \prime}$ & & 416 & 377 & 3.3 & 381 & 366 & $\varphi \mathrm{CH} \mathrm{m}$ \\
\hline 77. $\mathrm{A}^{\prime \prime}$ & & 387 & 351 & 3.7 & 349 & 335 & $\beta \mathrm{ClPCl}$ \\
\hline 78. $\mathrm{A}^{\prime \prime}$ & & 368 & 334 & 2.8 & 338 & 325 & $\varphi \mathrm{CH} \mathrm{m}$ \\
\hline 79. $\mathrm{A}^{\prime \prime}$ & & 347 & 314 & 1.9 & 319 & 306 & $\varphi \mathrm{CH} \mathrm{m}$ \\
\hline 80. $\mathrm{A}^{\prime \prime}$ & & 318 & 289 & 0.2 & 288 & 277 & $\varphi \mathrm{CH} \mathrm{m}$ \\
\hline 81. A" & & 308 & 280 & 0.3 & 280 & 270 & $\varphi \mathrm{CCC}$ ring \\
\hline 82. $\mathrm{A}^{\prime \prime}$ & & 247 & 224 & 0.4 & 231 & 222 & $\varphi C C C$ ring \\
\hline 83. $\mathrm{A}^{\prime \prime}$ & & 234 & 212 & 0.0 & 221 & 212 & $\varphi \mathrm{CCC}$ \\
\hline 84. A" & & 233 & 211 & 0.2 & 214 & 206 & $\beta \mathrm{ClPCl}$ \\
\hline 85. $\mathrm{A}^{\prime \prime}$ & & 222 & 201 & 0.4 & 196 & 188 & $\varphi \mathrm{POCC}$ \\
\hline 86. $\mathrm{A}^{\prime \prime}$ & & 204 & 185 & 0.5 & 185 & 178 & $\varphi \mathrm{ClPOC}$ \\
\hline 87. $\mathrm{A}^{\prime \prime}$ & & 180 & 163 & 1.7 & 163 & 157 & $\varphi \mathrm{CCC}$ \\
\hline 88. A" & & 142 & 129 & 1.6 & 129 & 124 & $\varphi \mathrm{CCC}$ \\
\hline $89 \quad \mathrm{~A}^{\prime \prime}$ & & 90 & 82 & 1.1 & 86 & 83 & $\varphi \mathrm{ClOClP}$ \\
\hline $90 \quad \mathrm{~A}^{\prime \prime}$ & & 79 & 72 & 0.5 & 70 & 67 & $\varphi \mathrm{CCC}$ \\
\hline $91 \quad \mathrm{~A}^{\prime \prime}$ & & 60 & 55 & 0.2 & 50 & 48 & $\varphi \mathrm{CCC}$ \\
\hline $92 \quad \mathrm{~A}^{\prime \prime}$ & & 57 & 52 & 0.2 & 46 & 44 & $\varphi \mathrm{CCC}$ \\
\hline $93 \quad \mathrm{~A}^{\prime \prime}$ & & 34 & 31 & 0.2 & 26 & 25 & $\varphi \mathrm{PCCl}$ \\
\hline
\end{tabular}

${ }^{a}$ s: strong; vs: very strong; m: medium; w: weak; vw: very weak. ${ }^{b} \gamma$ : stretching; $\beta$ : in-plane bending; $\varphi$ : out-of-plane bending; $I_{\mathrm{IR}}$ : IR intensity.

\subsubsection{Cyclohexane ring vibrations}

Cyclohexyl ring in MEPCL2 contains three methylene $\left(\mathrm{CH}_{2}\right)$ groups, each group has six modes of vibration namely asymmetric and symmetric stretching, scissoring, rocking, wagging and twisting modes. In general, in cyclohexane, the $\mathrm{CH}_{2}$ stretching vibrations are usually observed below $3000 \mathrm{~cm}^{-11}$. The asymmetric $\mathrm{CH}_{2}$ stretching vibration generally observed in the region is $3000-2900 \mathrm{~cm}^{-1}$ while the $\mathrm{CH}_{2}$ symmetric stretch is between 2900 and 2800 $\mathrm{cm}^{-1} 12,13$. In MEPCL2, the calculated wavenumbers at 2934, 2933, 2916, 2913, 2912, 2908 and $2906 \mathrm{~cm}^{-1}$ are attributed to asymmetric $\mathrm{CH}_{2}$ stretching vibrations, while the symmetric $\mathrm{CH}_{2}$ stretching wave numbers are calculated as 2899,2894 and $2877 \mathrm{~cm}^{-1}$ at the B3LYP/6-311++G(d,p) level of theory. One stretching vibration of cyclohexyl ring is observed in MEPCL2, as very strong band at $2928 \mathrm{~cm}^{-1}$ in FT-IR spectrum. The vibrations due to aromatic $\mathrm{C}-\mathrm{H}$ in-plane bending are observed in the region $1000-1300 \mathrm{~cm}^{-1}{ }^{14}$. For this compound, the $\mathrm{C}-\mathrm{H}$ in-plane bending vibrations were observed at 1224, 1180 and $1060 \mathrm{~cm}^{-1}$ in FT-IR. The theoretically scaled vibrations predicted at the y B3LYP/6-311++G(d,p) level are obtained at 1305, 1274, 1253, 1222, 1209, 1158,11421110 and $1066 \mathrm{~cm}^{-1}$. The $\mathrm{C}-\mathrm{H}$ out-of-plane bending vibrations are appearing within the region $900-675 \mathrm{~cm}^{-1}{ }^{15}$. The vibrations identified at 770 , 586,4985 and $447 \mathrm{~cm}^{-1}$ in FT-IR are assigned to C-H out-of-plane bending for MEPCL2.

\subsection{2. $C-C$ vibrations}

The ring stretching vibrations are useful to identify characteristic of the ring itself. For the title compound, the $\mathrm{C}=\mathrm{C}$ stretching vibrations are recorded at 1456 and $1388 \mathrm{~cm}^{-1}$ in FT-IR with medium intensities. All bands are appearing in the expected range, except first band. Most of the bands are observed with medium and strong intensities. The computed values are at 1459, 1456, 1453, 1441,1430 and $1427 \mathrm{~cm}^{-1}$ at the B3LYP/6-311++G(d,p) level of theory. The other C-C vibrations are computed at 1447, 1444, 1436, 1375 and $1366 \mathrm{~cm}^{-1}$. These vibrations are downshifted when they are compared with those exhibited by aromatic compounds and other $\mathrm{C}-\mathrm{C}$ vibrations are more shifted with ring C-C vibrations. Only two bands at 992 and $974 \mathrm{~cm}^{-1}$ are assigned to $\mathrm{C}-\mathrm{C}-\mathrm{C}$ in-plane bending vibrations of MEPCL2. The two bands are in infrared region with very strong intensities. The computed vibrations are tabulated to C-C-C in-plane and out-of-plane bending vibrations at 1001, 951, 921 and 270, 222 and $266 \mathrm{~cm}^{-1}$.

\subsubsection{Methyl group vibrations}

For the assignment of $\mathrm{CH}_{3}$ group frequencies, nine fundamental vibrations can be associated with each $\mathrm{CH}_{3}$ group. Three stretching, three bending, two rocking modes and single torsional mode describe the motion of the methyl group. In the experimental FT-IR band is observed at $2928 \mathrm{~cm}^{-1}$ for MEPCL2 have been assigned to $\mathrm{CH}_{3}$ symmetric stretching vibration. The $\mathrm{CH}_{3}$ stretching 
vibrations are calculated as 2893, 2916, 2913, 2912, 2908, 2906, 2899, 2894 and $2877 \mathrm{~cm}^{-1}$ at the B3LYP/6-311G++(d,p) level of theory. The FT-IR band observed at $1388 \mathrm{~cm}^{-1}$ have been assigned to $\mathrm{CH}_{3}$ in-plane bending vibration for MEPCL2.

\subsection{4. $\mathrm{P}-\mathrm{Cl}$ and $\mathrm{P}-\mathrm{O}$ vibrations}

The experimental $\mathrm{P}-\mathrm{Cl}$ stretching vibrations are observed in the interval $587-435 \mathrm{~cm}^{-1}$. Also, a band at $447 \mathrm{~cm}^{-1}$ is assigned as $\mathrm{P}-\mathrm{Cl}$ vibration. The calculated $\mathrm{P}-\mathrm{Cl}$ in-plane and out-of-plane bending vibrations are observed at 387,233 and $34 \mathrm{~cm}^{-1}$. The $\mathrm{P}-\mathrm{O}$ phenyl linkage gives rise to two bands. A strong band at $1260-1160 \mathrm{~cm}^{-1}$ is mainly due to the stretching of the $\mathrm{C}-\mathrm{O}$ bond of the phenyl group. Also, the band at $992 \mathrm{~cm}^{-1}$ is related to a C-O stretching vibration.

The simulated infrared spectra of MEPCL2 obtained at the HF/ 6-311G $++(d, p)$ and B3LYP/6-311G $++(d, p)$ levels of theory are shown in Fig. 3.

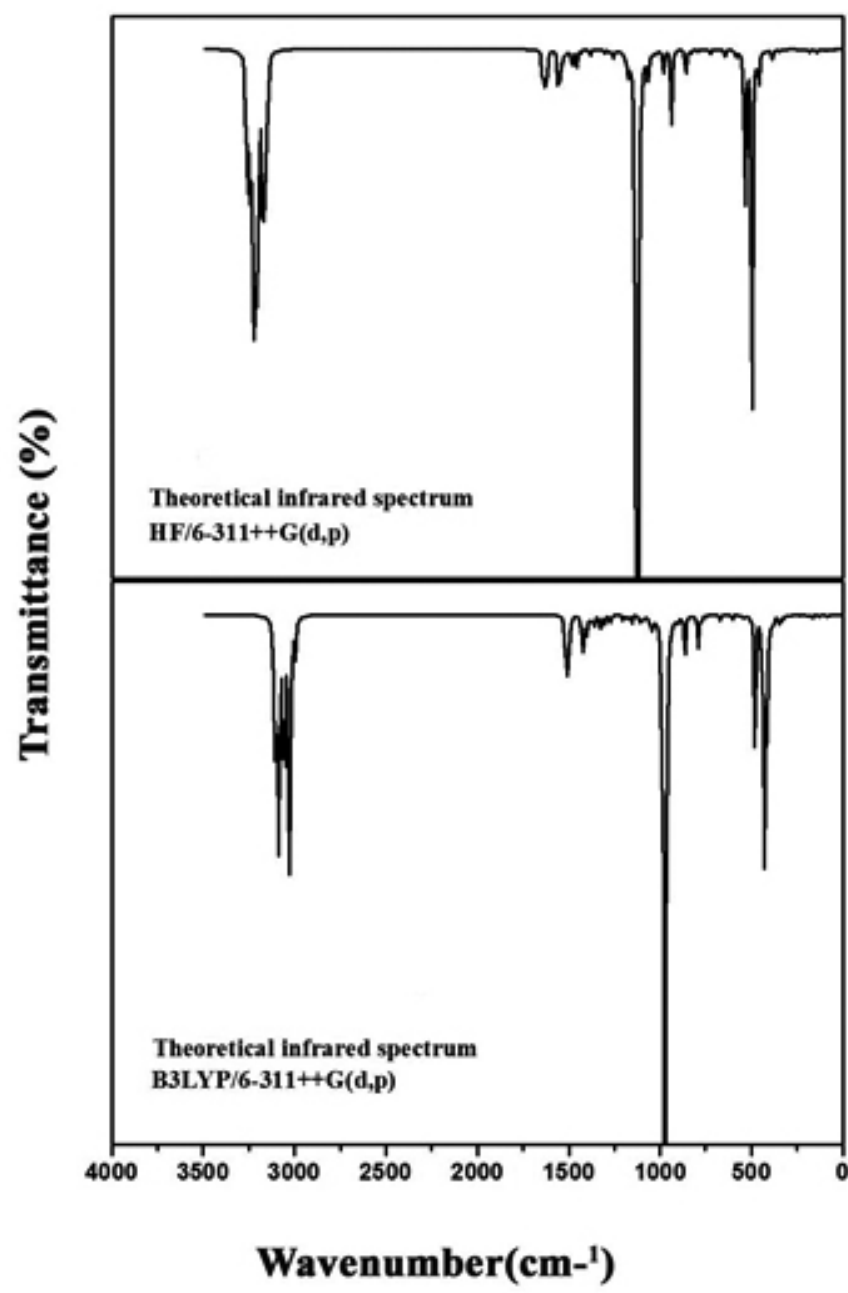

Fig. 3. Computed FT-IR spectra for MEPCL2

\subsection{Frontier molecular orbitals (FMOs)}

The highest occupied molecular orbital (HOMO) and the lowest-lying unoccupied molecular orbital (LUMO) may describe the electronic transition, non-linear optic properties, and UV-Vis spectra of a molecular system ${ }^{16}$. Also, the energy gap between HOMO and LUMO determines the kinetic stability, chemical reactivity and, optical polarizability and chemical hardnesssoftness of a molecule ${ }^{17,18}$. The hard molecules are less polarizable than the soft ones because they need big energy to excitation. The electronic calculated through the TD-DFT method. In order to evaluate the energetic behavior of MEPCL2 in the solvent, we carried out calculations considering acetonitrile, water, chloroform and gas phases. The energies of the four molecular orbitals of MEPCL2: the second highest and highest occupied MO's (HOMO and HOMO-1), the lowest and the second lowest unoccupied MO's (LUMO and LUMO+1) were calculated at the TD-DFT/B3LYP/6-311++G(d,p) level of theory and they are reported in Table 3. Also, the 3D plots of the HOMO1, HOMO, LUMO and LUMO+1 orbitals computed at TD-DFT/B3LYP/6$311++\mathrm{G}(\mathrm{d}, \mathrm{p})$ level of theory for MEPCL2 molecule are depicted in Fig. 4. It is clear from this figure that, while the HOMO is localized on almost the whole molecule, LUMO is especially localized on the ring. Also, note that both, the HOMOs and the LUMOs are mostly anti-bonding type orbitals.

The calculated energy values of the HOMO and LUMO energy gaps are $6.3017,6.3008,6.3085$ and $6.3183 \mathrm{eV}$ in acetonitrile, water, chloroform and gas phases, respectively. Thus, it is clear that the highest energy gap is obtained when chloroform solvent is employed which suggest that MEPCL2 is more chemically stable in such solvent. In view of calculated absorption spectra, the maximum absorption wavelength corresponds to the electronic transition from the HOMO to LUMO with $92 \%$ and from the HOMO to LUMO+1 with $9 \%$ contribution, see Table 4 . The other wavelength, excitation energies, oscillator strength and calculated counterparts with major contributions are listed in Table 4

Table 3. Computed energy values of MEPCL2 in acetonitrile, water, chloroform and gas.

\begin{tabular}{|c|c|c|c|c|}
\hline $\begin{array}{c}\text { TD-DFT/B3LYP/ } \\
6-311++\mathrm{G}(\mathrm{d}, \mathrm{p})\end{array}$ & Acetonitrile & Water & Chloroform & Gas \\
\hline $\mathrm{E}_{\text {total }}$ (Hartree) & -1729.77 & -1729.77 & -1729.76 & -1729.76 \\
\hline $\mathrm{E}_{\text {номо }}(\mathrm{eV})$ & -7.90 & -7.91 & -7.89 & -7.85 \\
\hline $\mathrm{E}_{\text {LUMO }}(\mathrm{eV})$ & -1.60 & -1.61 & -1.58 & -1.54 \\
\hline$\Delta \mathrm{E}_{\text {HOMO-LUMO gap }}(\mathrm{eV})$ & 6.30 & 6.30 & 6.31 & 6.32 \\
\hline $\mathrm{E}_{\text {номо-1 }}(\mathrm{eV})$ & -8.05 & -8.05 & -8.08 & -8.19 \\
\hline $\mathrm{E}_{\mathrm{LUMO}+1}(\mathrm{eV})$ & -1.18 & -1.18 & -1.58 & -1.14 \\
\hline$\Delta \mathrm{E}_{\text {HOMO-1-LUMO+1 gap }}(\mathrm{eV})$ & 6.87 & 6.86 & 6.50 & 7.05 \\
\hline $\mathrm{E}_{\text {номо-2 }}(\mathrm{eV})$ & -8.18 & -8.18 & -8.21 & -8.34 \\
\hline $\mathrm{E}_{\mathrm{LUMO}+2}(\mathrm{eV})$ & -0.24 & -0.24 & -0.28 & -0.43 \\
\hline$\Delta \mathrm{E}_{\mathrm{HOMO}-2-\mathrm{LUMO}+2 \text { gap }}(\mathrm{eV})$ & 7.94 & 7.94 & 7.93 & 7.92 \\
\hline
\end{tabular}

Note that the calculations of the molecular orbital show that the visible absorption maxima of MEPCL2 corresponds to the electron transition between frontier orbitals such as translation from HOMO to LUMO, see Table 4. The calculated absorption spectra showed five bands at 227.8, 220.9, 211.5 208.9 and $201.6 \mathrm{~nm}$ for acetonitrile and at $227.2 \mathrm{~nm}$ in the experimental UV spectrum with maximum absorbance in the same solvent. In chloroform, water and gas phases, the theoretical maximum absorption bands are predicted at 228.2, 227.8 and $226.2 \mathrm{~nm}$, respectively. All the maximum absorption bands are coming from HOMO to LUMO transition with energy contribution about 96 to $97 \%$. The next maximum peaks are predicated on HOMO-1 to LUMO+1 in all UV spectra with 80 to $90 \%$ around $200 \mathrm{~nm}$. In Fig. 5 are shown the theoretical UV spectra obtained at the TD-DFT/6-311++G(d,p) level of theory, in all cases, it is possible to observe that the maximum absorbance is in the range $226-228 \mathrm{~nm}$. 

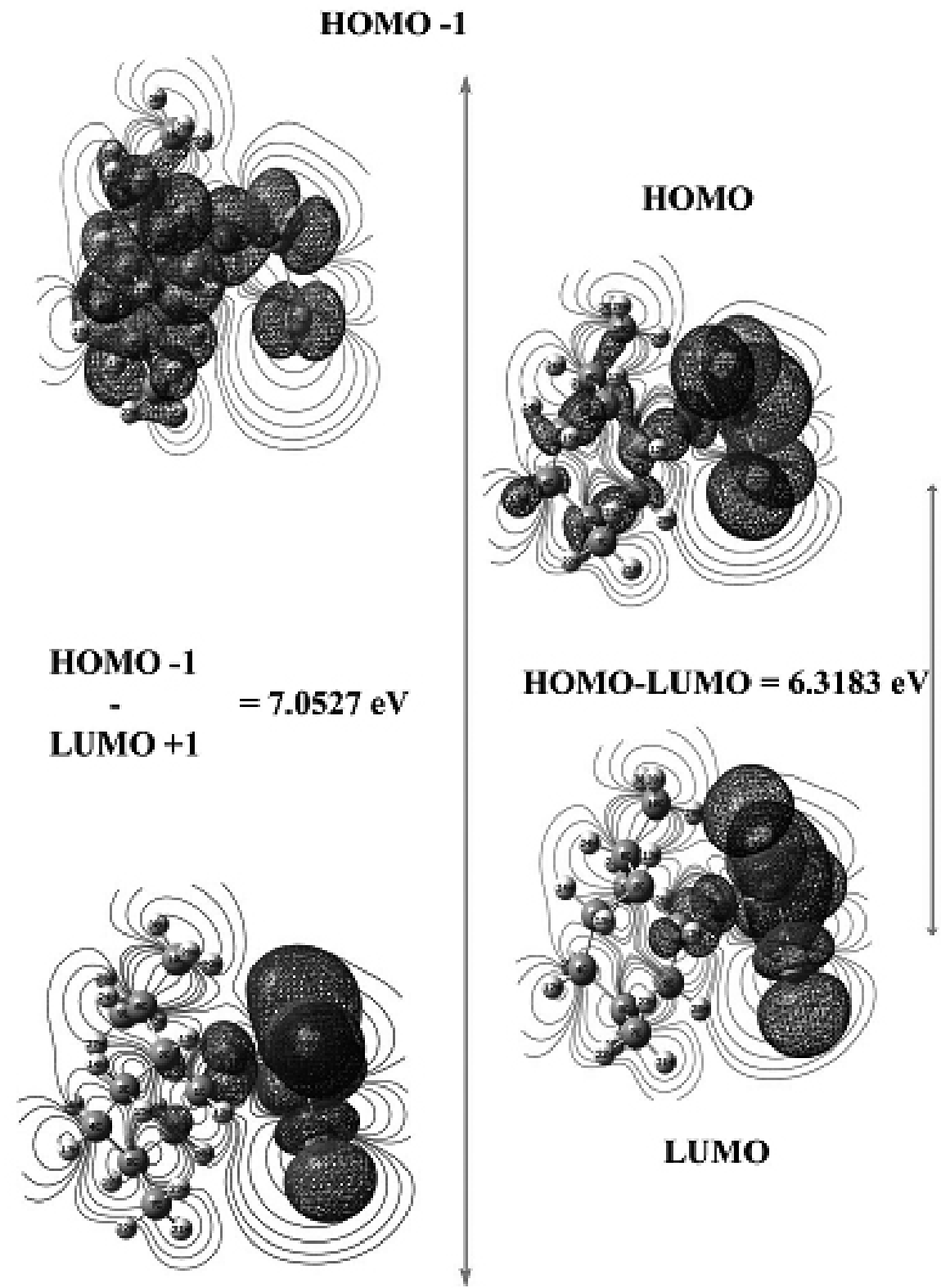

\section{LUMO}

\section{LUMO + 1}

Fig. 4. 3D view of HOMO and LUMO diagram with energy gaps.

3.4. ${ }^{1} \mathrm{H}$ and ${ }^{13} \mathrm{C}$ NMR spectra from quantum calculations

The theoretical values for ${ }^{1} \mathrm{H}$ and ${ }^{13} \mathrm{C}$ NMR of MEPCL2 are given in Table 5. The theoretical ${ }^{1} \mathrm{H}$ and ${ }^{13} \mathrm{C}$ NMR chemical shifts of MEPCL2 have been compared with the experimental data measured in water and $\mathrm{CDCl}_{3}$ solvents.

A comparison, between the experimental and computed ${ }^{13} \mathrm{C}$ NMR spectra of MEPCL2, indicates an increase in the value of the chemical shifts of the carbon atoms $\mathrm{C} 1$ and $\mathrm{C} 2$ of cyclohexane, due to heavy substitutions, which is caused by the electronic charge distribution around of these carbon atoms.

The hydrogen peaks in the cyclohexane are observed experimentally from 2.228 to $1.331 \mathrm{ppm}$, while that the evaluated at the B3LYP/6-311+G (d,p) level of theory are in the range $2.238-1.174 \mathrm{ppm}$.

The methyl hydrogen atom $\mathrm{H} 22$ peak identified at $0.809 \mathrm{ppm}$ is the lowest chemical shift among the entire hydrogen atoms. Probably, it is because of its electronic interaction with other atoms is lesser. The correlation graphs of the experimental and theoretical ${ }^{1} \mathrm{H}$, and ${ }^{13} \mathrm{C}$ NMR chemical shift are presented as supplementary material in Fig 6. A good correlation between predicted and observed ${ }^{13} \mathrm{C}$ and ${ }^{1} \mathrm{H}$ NMR chemical shifts is found. Moreover, the slope and intercept of the least-square, correlation lines were used to scale the GIAO isotropic absolute shielding constants. From Fig. 6 it is clear that the solvent water shows more deviation that the observed in the $\mathrm{CDCl}_{3}$ solvent. The relation is usually linear and described by the following equations (1-4): 
J. Chil. Chem. Soc., 63, No 1 (2018)

Table 4. Theoretical electronic absorption spectra of MEPCL2 excitation energies E (eV), (absorption wavelength $\lambda$ (nm), and oscillator strengths $(f)$ using TD-DFT/B3LYP/6-311++G(d,p) method.

\begin{tabular}{|c|c|c|c|c|}
\hline Solvent & Energy $(\mathrm{eV})$ & Wavelength & Oscillator strength & Major contribution \\
\hline \multirow{5}{*}{ Acetonitrile } & 5.4418 & 227.8 & 0.0794 & HOMO->LUMO (96\%) \\
\hline & 5.6102 & 220.9 & 0.0005 & H-2->LUMO (10\%), H-1->LUMO (80\%) \\
\hline & 5.8609 & 211.5 & 0.0014 & H-2->LUMO (84\%), H-1->LUMO (11\%) \\
\hline & 5.9338 & 208.9 & 0.0332 & H-5->LUMO (10\%), H-4->LUMO (15\%), HOMO->L+1 (69\%) \\
\hline & 6.1502 & 201.6 & 0.0558 & $\mathrm{H}-1->\mathrm{L}+1(87 \%)$ \\
\hline \multirow{4}{*}{ Water } & 5.6072 & 221.1 & 0.0005 & H-2->LUMO (10\%), H-1->LUMO (80\%) \\
\hline & 5.8559 & 211.7 & 0.0014 & H-2->LUMO (84\%), H-1->LUMO (11\%) \\
\hline & 5.9353 & 208.9 & 0.0330 & H-5->LUMO (13\%), H-4->LUMO (11\%), HOMO->L+1 (70\%) \\
\hline & 6.1475 & 201.7 & 0.0554 & H-1->L+1 (87\%) \\
\hline \multirow{4}{*}{ Chloroform } & 5.4331 & 228.2 & 0.0839 & HOMO->LUMO (97\%) \\
\hline & 5.9147 & 209.6 & 0.0095 & H-2->LUMO (67\%), HOMO->L+1 (18\%) \\
\hline & 5.9202 & 209.4 & 0.0260 & H-4->LUMO (19\%), H-2->LUMO (18\%), HOMO->L+1 (50\%) \\
\hline & 6.1769 & 200.7 & 0.0579 & $\mathrm{H}-1->\mathrm{L}+1(84 \%)$ \\
\hline \multirow{5}{*}{ Gas } & 5.4788 & 226.2 & 0.0579 & HOMO->LUMO $(96 \%)$ \\
\hline & 5.7101 & 217.1 & 0.0612 & H-1->LUMO (81\%) \\
\hline & 5.9263 & 209.2 & 0.0002 & H-3->LUMO (24\%), HOMO->L+1 (55\%) \\
\hline & 6.0786 & 203.9 & 0.0146 & H-2->LUMO (89\%) \\
\hline & 6.2299 & 199.0 & 0.0003 & H-1->L+1 (80\%) \\
\hline
\end{tabular}
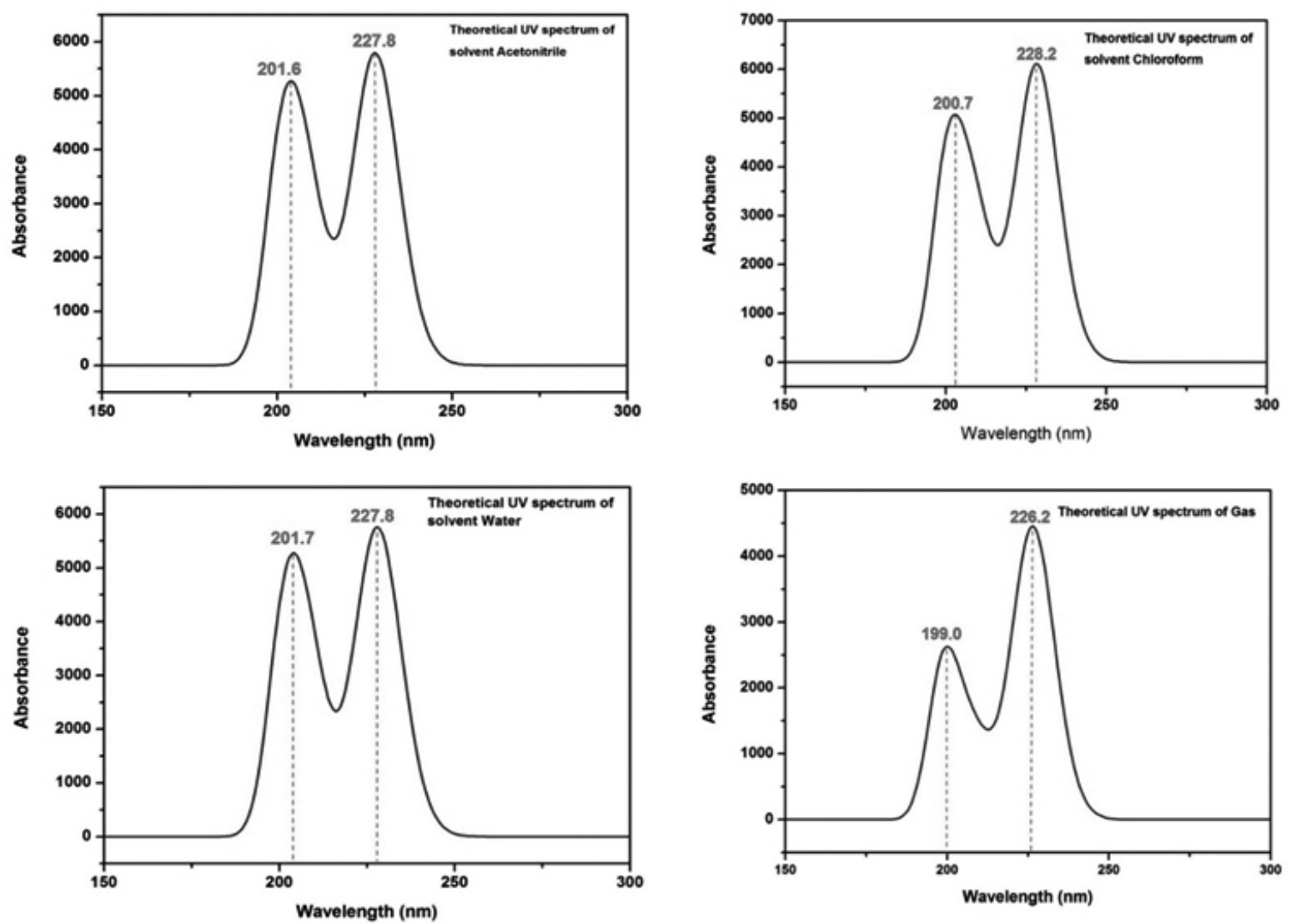

Fig. 5. Computed UV-Vis graphs in different solvent for MEPCL2. 

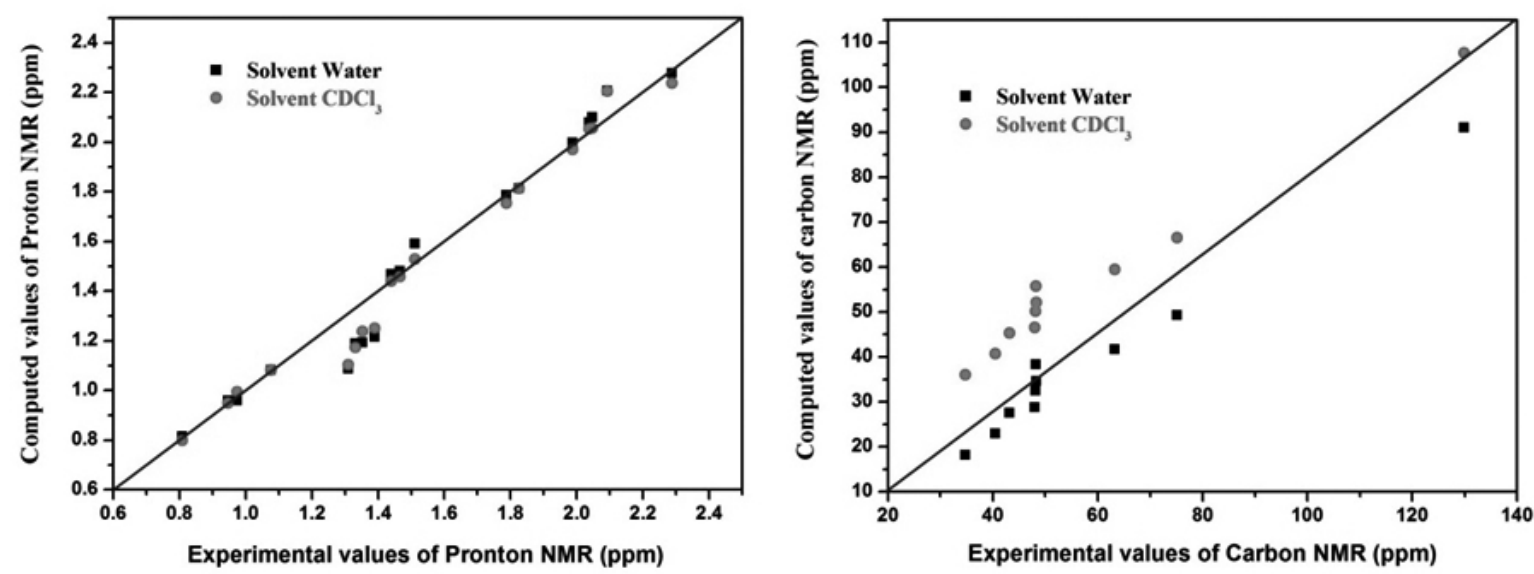

Fig. 6. Correlation Proton and Carbon NMR between experimental and computed data.

Proton NMR

$v=-0.1286+1.06991 v_{\text {exp }} \quad\left(\mathrm{R}^{2}=0.96503\right)$ in solvent water $v_{\text {cal. }}=-0.0923+1.03958 v_{\text {exp. }}^{\text {exp. }}\left(\mathrm{R}^{2}=0.97219\right)$ in solvent $\mathrm{CDCl}_{3}$

Carbon NMR:

$v_{\text {cal. }}=-3.86793+0.73135 v_{\text {exp. }}\left(\mathrm{R}^{2}=0.97407\right)$ in solvent water

$v_{\text {cal. }}=14.31258+0.0 .72025 v_{\text {exp. }}\left(\mathrm{R}^{2}=0.97442\right)$ in solvent $\mathrm{CDCl}_{3}$

These results indicate that the calculations performed at the B3LYP/6$311++\mathrm{G}(\mathrm{d}, \mathrm{p})$ predicted adequately the experimental behavior of the ${ }^{1} \mathrm{H}$ and ${ }^{13} \mathrm{C}$ NMR spectra of MEPCL2.

\subsection{Global Chemical Reactivity of MEPCL2}

The reactivity of a molecular system can be analyzed employing the global reactivity descriptors derived from the DFT theory, which are evaluated through the total energies of the neutral, anionic and cationic systems. Thus, the ionization potential is determined from the energy difference between the energy of the compound derived from electron-transfer (radical cation) and the respective neutral compound; $\mathrm{IP}=\mathrm{E} \quad-\mathrm{E}$; while the electron affinity is evaluated as the energy difference between the neutral molecule and the anion molecule: $\mathrm{EA}=\mathrm{E}_{\mathrm{n}}-\mathrm{E}_{\text {anion }}$. According to the Koopmans' theorem, in HF calculations, ionization potentials (IP) and electron affinities (EA) may be approximated to the HOMO and LUMO's energies respectively. On the other hand, the validity of the Koopmans' theorem within the DFT approximation is controversial, nonetheless, it has been shown that the Khon-Sham orbitals produce DFT reactivity descriptors that correlate quite well with the reactivity descriptors obtained from Hartree-Fock calculations ${ }^{19}$. Thus, in the present work, we decided to employ the second approximation. Additionally, from IP and EA values it is possible to evaluate the electronegativity $(\chi)$, hardness $(\eta)$,

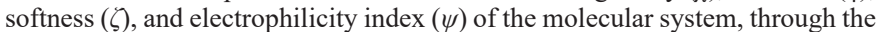
equations $(5-8)^{20}$

Electronegativity $(\chi): \mu \approx-\chi=-\frac{\mathrm{IP}+\mathrm{EA}}{2}$

Chemical hardness $(\eta) \approx \frac{\text { IP }- \text { EA }}{2}$

Softness $(\zeta)=\frac{1}{2 \eta}$

Electrophilicity index $(\psi)=\frac{\mu^{2}}{2 \eta}$

The values of electronegativity, chemical hardness, softness, electrophilicity index and dipolar moment are reported in Table 6 , in the solvents acetonitrile, water, chloroform and gas phases.
Table 5. Experimental and theoretical probable ${ }^{1} \mathrm{H}$ and ${ }^{13} \mathrm{C}$ NMR isotropic chemical shifts (with respect to TMS and in Water and $\mathrm{CDCl}_{3}$ solution) of MEPCL2 compound.

\begin{tabular}{|c|c|c|c|}
\hline \multirow[t]{2}{*}{ Atom } & \multirow[t]{2}{*}{ Experimental $(\mathrm{ppm})^{7}$} & \multicolumn{2}{|c|}{ Theoretical (B3LYP) (ppm) } \\
\hline & & Water & $\mathrm{CDCl}_{3}$ \\
\hline H12 & & 5.123 & 5.085 \\
\hline H19 & 2.288 & 2.277 & 2.238 \\
\hline H13 & 2.092 & 2.207 & 2.206 \\
\hline H15 & 2.047 & 2.100 & 2.056 \\
\hline H18 & 2.038 & 2.080 & 2.053 \\
\hline $\mathrm{H} 16$ & 1.988 & 1.998 & 1.970 \\
\hline $\mathrm{H} 20$ & 1.826 & 1.814 & 1.813 \\
\hline $\mathrm{H} 24$ & 1.788 & 1.786 & 1.754 \\
\hline $\mathrm{H} 27$ & 1.511 & 1.591 & 1.529 \\
\hline $\mathrm{H} 23$ & 1.466 & 1.480 & 1.459 \\
\hline $\mathrm{H} 14$ & 1.439 & 1.468 & 1.441 \\
\hline $\mathrm{H} 26$ & 1.390 & 1.214 & 1.250 \\
\hline H29 & 1.353 & 1.192 & 1.237 \\
\hline H17 & 1.331 & 1.189 & 1.174 \\
\hline $\mathrm{H} 28$ & 1.310 & 1.087 & 1.103 \\
\hline $\mathrm{H} 25$ & 1.077 & 1.082 & 1.082 \\
\hline $\mathrm{H} 21$ & 0.975 & 0.958 & 0.995 \\
\hline H30 & 0.947 & 0.958 & 0.950 \\
\hline $\mathrm{H} 22$ & 0.809 & 0.814 & 0.799 \\
\hline $\mathrm{C} 1$ & 129.88 & 91.018 & 107.714 \\
\hline $\mathrm{C} 2$ & 75.14 & 49.268 & 66.567 \\
\hline $\mathrm{C} 8$ & 63.21 & 41.677 & 59.452 \\
\hline C6 & 48.24 & 38.348 & 55.768 \\
\hline $\mathrm{C} 5$ & 48.26 & 34.568 & 52.099 \\
\hline $\mathrm{C} 3$ & 48.15 & 32.526 & 50.223 \\
\hline $\mathrm{C} 4$ & 48.01 & 28.808 & 46.545 \\
\hline C10 & 43.19 & 27.558 & 45.318 \\
\hline C9 & 40.47 & 22.992 & 40.696 \\
\hline $\mathrm{C} 7$ & 34.74 & 18.220 & 35.978 \\
\hline
\end{tabular}


Table 6. Computed electronegativity, chemical hardness-softness, and dipolar moment of MEPCL2 in acetonitrile, water, chloroform and gas phases.

\begin{tabular}{|c|c|c|c|c|}
\hline $\begin{array}{c}\text { B3LYP/ } \\
6-311++\mathrm{G}(\mathrm{d}, \mathrm{p})\end{array}$ & Acetonitrile & Water & Chloroform & Gas \\
\hline $\begin{array}{c}\text { Electronegativity } \chi \\
(\mathrm{eV})\end{array}$ & 4.75 & 4.76 & 4.74 & 4.70 \\
\hline $\begin{array}{c}\text { Chemical hardness } \\
\eta(\mathrm{eV})\end{array}$ & 3.15 & 3.15 & 3.15 & 3.16 \\
\hline \begin{tabular}{c} 
Softness $\zeta(\mathrm{eV})^{-1}$ \\
\hline $\begin{array}{c}\text { Electrophilicity index } \\
\psi(\mathrm{eV})\end{array}$
\end{tabular} & 3.59 & 3.59 & 3.55 & 3.16 \\
\hline $\begin{array}{c}\text { Dipolar moment } \\
(\text { Debye })\end{array}$ & 3.87 & 3.89 & 3.67 & 3.15 \\
\hline
\end{tabular}

From these values, observe that the values of $\chi, \eta, \zeta$, and $\psi$ are similar, this means that MEPCL2 is showing the same global chemical behavior in the different solvents, but it is clear that the dipolar moment has different values which depend on the solvent in where the molecule is immersed. The above mentioned is indicative of the presence of different intramolecular interactions between the solvent and MEPCL2.

3.6. Local reactivity of MEPCL2 from Molecular Electrostatic Potential

In the present study, the molecular electrostatic potential (MESP) of MEPCL2 is plotted in order to analyze its local reactivity, see Fig. 7. The MESP is a plot of the electrostatic potential mapped onto an electron density isosurface and is useful to identify electrophilic and nucleophilic regions around the molecule. In the majority of the MESP, while the maximum negative region, which preferred site for electrophilic attack indications as red color, the maximum positive region which preferred site for nucleophilic attack symptoms as blue color. The electrophilic attack is more around phosphorous and carbon atoms. It is extended around chlorine atoms. Similarly, nucleophilic attacks are shown in hydrogen atoms and more in methyl group substitutions. The different values of the electrostatic potential at the MESP surface are represented by different colors; red, blue and green represent the regions of most negative, most positive and zero electrostatic potential, respectively. The color code of these maps is in the range between -0.02335 e. (deepest red) to $0.02335 \mathrm{e}$ (deepest blue) in the compound, where blue indicates the stronges attraction and red indicates the strongest repulsion ${ }^{21-26}$.

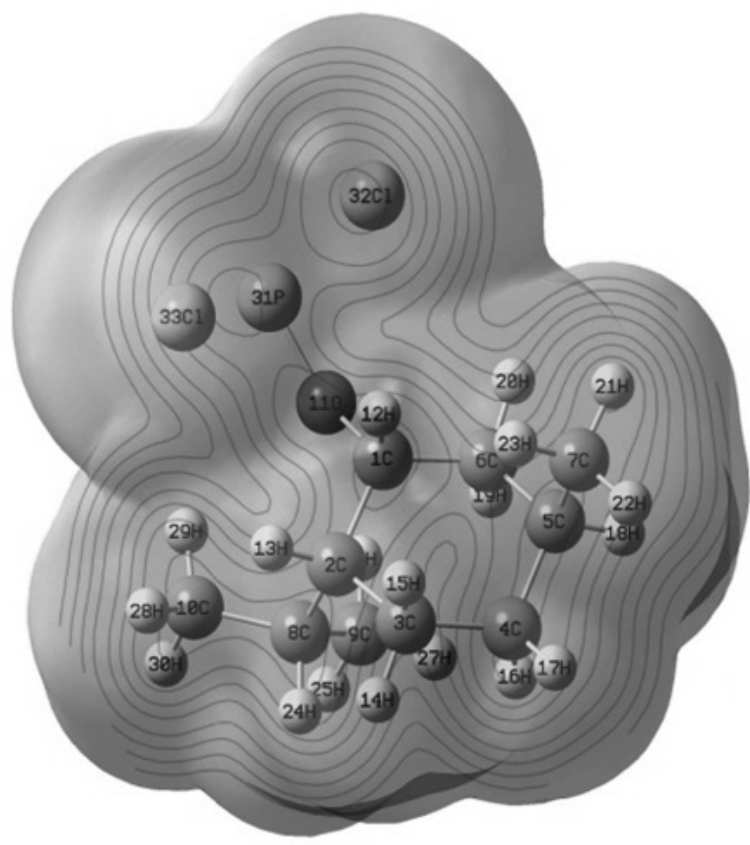

Fig. 7. Molecular electrostatic potential (MESP) of MEPCL2

\section{CONCLUSIONS}

In this work, the geometric parameters and vibrational frequencies of the mentoxy dichloro phosphorous $\left(\mathrm{C}_{10} \mathrm{H}_{10 P C l}\right)$ were evaluated at the $\mathrm{HF} / 6$ $311++\mathrm{G}(\mathrm{d}, \mathrm{p})$ and $\mathrm{B} 3 \mathrm{LYP} / 6-311++\mathrm{G}(\mathrm{d}, \mathrm{p})$ levels of theory. In comparison to the experimental results, the computed vibrational frequencies obtained by the B3LYP method are better than those obtained by the Hartree-Fock method. Fundamental vibrations with their mode were fully discussed in order to give a better understanding of the electronic structure of MEPCL2. The HOMO-LUMO gaps and implications of the electronic transitions were examined. The kinetic stability, chemical reactivity, optical polarizability, and chemical hardness-softness were discussed by frontier molecular orbital gaps. With orbital analysis, it has been suggested that MEPCL2 is more stable in chloroform than in other solvents. The ${ }^{1} \mathrm{H}$, and ${ }^{13} \mathrm{C}$ NMR recorded and isotropic chemical shifts were calculated and they compare favorably well with the experimental results. The evaluation of the global reactivity descriptors suggests a similar chemical behavior of MEPCL2 in the different solvents analyzed. The molecular electrostatic potential isosurface provides a visual performance of the chemically active sites and comparative reactivity of atoms. Thus the present investigation provides complete vibrational assignments, structural information, chemical shifts and electronic properties of the MEPCL2.

\section{ACKNOWLEDGEMENTS}

The authors gratefully acknowledge the financial support from the Research Council of Imam Khomeini International University. Also, the authors greatly appreciate Prof. M. Govindarajan for valuable comments and discussions. LHMH expresses his gratitude to the Mexican National Council for Science and Technology (CONACYT) for financing this work through the Research Project Grant 257823 and to the Universidad Autónoma del Estado de Hidalgo. The authors gratefully acknowledge too the financial support of research Direction UCSC.

\section{REFERENCES}

1. Sengupta, S. K., Pandey, O. P., Rao, G. P., Vishen, P.: Metal Based Drugs. 8, $293(2002)$

2. Suarez, P., Dullius, J.E. L., Einloft, S., De Souza, R., Dupont, R.: J. Inorg. Chim. Acta. 255, 207-209 (1997)

3. Boon, A., Levisky, J. L., Pflug, L., Wilkes, J. S.: J. Inorg. Chem. 51, 480 $483(1986)$

4. Yanes, E. G., Gratz, S. R., Baldwin, M. J., Robinson, S.E., Stalcup, A. M. Anal. Chem. 73, 3838 (2001)

5. Racke, K.D.: Degradation of organophosphorus insecticides in environmental matrices. in: Chambers, J.E., Levi, P.E. (eds.) Organophosphates: Chemistry, Fate, and Effects. Academic Press, San Diego. 47-73 (1992)

6. Quin, L. D.: A Guide to Organophosphorus Chemistry; John Wiley \& Sons, (2000).

7. Mendoza-Huizar, L.H., J. Mex. Chem. Soc, 5(4) 416 (2014)

8. Gaussian 03, Revision C.02, Frisch, M. J.; Trucks, G. W.; Schlegel, H. B.; Scuseria, G. E.; Robb, M. A.; Cheeseman, J. R.; Montgomery, Jr., J. A.; Vreven, T.; Kudin, K. N.; Burant, J. C.; Millam, J. M.; Iyengar, S. S.; Tomasi, J.; Barone, V.; Mennucci, B.; Cossi, M.; Scalmani, G.; Rega, N.; Petersson, G. A.; Nakatsuji, H.; Hada, M.; Ehara, M.; Toyota, K.; Fukuda, R.; Hasegawa, J.; Ishida, M.; Nakajima, T.; Honda, Y.; Kitao, O.; Nakai, H.; Klene, M.; Li, X.; Knox, J. E.; Hratchian, H. P.; Cross, J. B.; Bakken, V.; Adamo, C.; Jaramillo, J.; Gomperts, R.; Stratmann, R. E.; Yazyev, O.; Austin, A. J.; Cammi, R.; Pomelli, C.; Ochterski, J. W.; Ayala, P. Y.; Morokuma, K.; Voth, G. A.; Salvador, P.; Dannenberg, J. J.; Zakrzewski, V. G.; Dapprich, S.; Daniels, A. D.; Strain, M. C.; Farkas, O.; Malick, D. K.; Rabuck, A. D.; Raghavachari, K.; Foresman, J. B.; Ortiz, J. V.; Cui, Q.; Baboul, A. G.; Clifford, S.; Cioslowski, J.; Stefanov, B. B.; Liu, G.; Liashenko, A.; Piskorz, P.; Komaromi, I.; Martin, R. L.; Fox, D. J.; Keith, T.; Al-Laham, M. A.; Peng, C. Y.; Nanayakkara, A.; Challacombe, M.; Gill, P. M. W.; Johnson, B.; Chen, W.; Wong, M. W.; Gonzalez, C.; and Pople, J. A.; Gaussian, Inc., Wallingford CT, 2004.

9. Karabacak, M., Kurt, M.: Spectrochim. Acta A. 71, 876-883 (2008).

10. Jamróz, M.H.: Vibrational Energy Distribution Analysis, VEDA 4, Warsaw, (2004).

11. Kemp, W.: Organic Spectroscopy, Mac Millan Press Ltd., London, (1991).

12. Shishkov, I.F., Sadova, N.I., Novikov, V.P., Vilkov, L.V., Strukt. Khim, Zh.: 25 (1984) 98-102. 
13. Sinha, L., Karabacak, M., Narayan, V., Cinar, M., Prasad, O.: Spectrochim. Acta

14. 109A, 298-307 (2013)

15. Socrates, G.: Infrared and Raman Characteristic Group Frequencies Tables and Charts. third ed., Wiley, New York, (2001).

16. Karabacak, M., Karagoz, D., Kurt, M.: J. Mol. Struct., 892, 25-31 (2008).

17. Rani, A.U., Sundaraganesan, N., Kurt, M., Cinar, M., Karabacak, M.: Spectrochim. Acta A 75, 1523-1529 (2010)

18. Balachandran, V., Lakshmi, A., Janaki, A.: Spectrochimica Acta A 81, 1-7 (2011)

19. Bevan Ott, J., Boerio-Goates, J.: Calculations from Statistical Thermodaynamics, Academic Press, (2000)

20. Martínez-Araya, J.I., Salgado-Morán, G., Glossman-Mitnik, D. J. Chem.,
2013, 1 (2013)

21. Krishnakumar, V., John Xavier, R.: Indian J. Pure Appl. Phys., 41, 597 (2003).

22. Lashgari, A., Ghamami, S., Salgado-Morán, G., Ranirez-Tagle, R., Lorena Gerli - Candia, Journal of the Chilean Chemical Society, 61(1), 2821-2827 (2016).

23. Lashgari, A., Ghammamy, S., Ramirez-Tagle, R., Salgado-Moran, G., Journal of Structural Chemistry, 56(8), 1505-1513, (2015).

24. Ghamami, S., Shahbazkhany, S., Lashgari, A., International Journal of Pure and Applied Chemistry, 9(1-2), 57-62 (2014).

25. Ghamami, S., Lashgari, A., Open Access Library Journal, 1: e422 (2014).

26. Lashgari, A., Ghammamy, S., Shahsavari, M., Asian Journal of Research in Chemistry, 7(7), 677-680 (2014) 